\title{
A framework to promote social sustainability in industry 4.0
}

\section{Alessandra Papetti and Monica Pandolfi}

Department of Industrial Engineering and Mathematical Sciences, Università Politecnica delle Marche, via Brecce Bianche 12, 60131 Ancona, Italy

Email: a.papetti@univpm.it

Email: m.pandolfi@univpm.it

\section{Margherita Peruzzini*}

Department of Engineering "Enzo Ferrari”, University of Modena and Reggio Emilia, via Vivarelli 10, 41125 Modena, Italy Email: margherita.peruzzini@unimore.it

${ }^{*}$ Corresponding author

\section{Michele Germani}

Department of Industrial Engineering and Mathematical Sciences, Università Politecnica delle Marche, via Brecce Bianche 12, 60131 Ancona, Italy

Email: m.germani@univpm.it

\begin{abstract}
Industrial process digitalisation is pervading numerous areas of production system, including sustainability. The study presents a method to affirm how the social sustainability of a company also passes through the protection of the welfare of the worker and describes a case study focused on small and medium-sized enterprises (SMEs). The method considers different aspects including the characteristics of the worker/s, the working context, and the content of the work activity. According to the objectives of social sustainability in the factory environment multifactorial variables related to the workers wellbeing have been defined. IoT system and ad-hoc questionnaires can be used to collect such variables. Following the proposed method, the results of the case study offer many in-depth insights, from the objective analysis of personal characteristics to the organisation of work, and from the application of international standards to the evaluation of psychological parameters.
\end{abstract}

Keywords: social sustainability; human-centred manufacturing; ergonomics; human factors; industry 4.0; IoT; internet of things; worker wellbeing; user-centred workplace.

Reference to this paper should be made as follows: Papetti, A., Pandolfi, M., Peruzzini, M. and Germani, M. (2020) 'A framework to promote social sustainability in industry 4.0', Int. J. Agile Systems and Management, Vol. 13, No. 3, pp.233-257. 
Biographical notes: Alessandra Papetti is Post-Doctoral researcher in Sustainability and Industrial System Management. Her research topics are methods and tools for sustainability and information management. She is the author of several scientific papers published on international journals and conference proceedings.

Monica Pandolfi is a Research Fellow at Università Politecnica delle Marche. She has skills and on-field experience on ergonomics, management of health, safety, security, or industrial hygiene programs, health promotion programs, and quality-health-safety-environmental (QHSE) strategies.

Margherita Peruzzini is an Associate Professor at the Department of Engineering "Enzo Ferrari", University of Modena and Reggio Emilia. She co-founded XiLab (X-in-the-Loop Simulation) (www.xilab.unimore.it) and coordinates VipLAB (Virtual Prototyping Lab). Her topics of research are virtual prototyping and industrial applications, human-centred design, humancomputer interaction and human-machine interfaces, collaborative virtual environments, co-design, and product-service systems. She is author of more than 130 publications on international journals and conference proceedings and Guest Editors for several international journals. She was Program Chair of several recent international conferences (FAIM2017, TE2017, TE2016) and Conference Chair of TE2018.

Michele Germani is Full Professor in Mechanical Design and Lifecycle Product Design. He is member of ASME, ADM and Design Society, he is Reviewer for several international scientific journals. Since 2011, he is a member of the Scientific Committee of the Masters in Smart Home Engineering and Scientific Director of the Framework Agreement 'Campus' for research and teaching in the Faculty of Engineering of his University. He is author of more of 150 international publications on journals and conference proceedings.

This paper is a revised and expanded version of a paper entitled 'Improving a production site from a social point of view: An IoT infrastructure to monitor workers condition' presented at 51st CIRP Conference on Manufacturing Systems, Stockholm, Sweden, 16-18 May, 2018.

\section{Introduction}

Although the fourth industrial revolution focuses on digitalisation of processes, it cannot neglect the sustainable development goals (United Nations, 2015). In particular, new social challenges imply sustainable work environments that promote healthy life, wellbeing for all at all ages and job satisfaction. Moreover, 'human-centricity' will play a key role in factories of the future to achieve flexibility, agility, and competitiveness. Accordingly, also human factors have been integrated with other existing models (i.e., cost estimation and lifecycle assessment) to evaluate a global manufacturing process sustainability (Peruzzini and Pellicciari, 2017).

Social sustainability in production sites includes workers' rights, preventive occupational health and safety, human-centred design of work, workers' empowerment, individual and collective learning, employee participation, and work-life balance. Improving workplace practices beyond legal compliance can result in higher morale and job satisfaction. All these concepts aim to preserve or build up human capital, and they 
represent a conscious way to deal with human resources. In 2014, Zink (2014) focuses on the needs of adopting sustainable production system, including also the human and social capital (e.g., health, motivation, participation, trustworthiness, skills, knowledge, identification). Docherty et al. (2009) stated that the opportunity to develop as a person, a professional and a member of a society through work experiences is a basic human right.

If transforming a company from profit-motivated to environmental sustainabilityfocused requires a nature-centred leadership process (Midouhas, 2017), the social dimension remarked the key role played by ergonomics and human factors also in the new manufacturing paradigms (Siemieniuch et al., 2015). Indeed, in social sustainability, ergonomics would be one of the main aspects integrated into the health and safety requirements (Jasiulewicz-Kaczmarek, 2013). The term ergonomics concerned with the study of work to fit with people. In 2013, among the people in the EU-28 7.9\% reported work-related health problems, which mainly refers to musculoskeletal disorders $(60.1 \%)$ and stress, depression and anxiety (15.9\%) (Eurostat, 2019). From this viewpoint, the majority of workplace accidents and diseases are preventable; therefore, it is necessary to promote a sustainable prevention and encourage greater participatory efforts to achieve safer and healthier workplaces. It means to apply ergonomics principles to the entire organisation considering physical, cognitive, social, environmental and organisational aspects together.

Moreover, the digital transformation is changing the modern factories with a potential great advantage for their sustainability. Indeed, within the so-called 'smart factory' new competencies and skills to handle with digital systems are requested (The Boston Consulting Group, 2015); at the same time, the factory workers become 'operators 4.0' (Peruzzini et al., 2020) and have to interact with new manufacturing systems, the socalled cyber-physical systems (CPS). In this contest, the definition and implementation of participatory ergonomics programs could enhance people awareness, increases acceptance of control implementations and effectively support the adoption of the worker-centred approach (Burgess-Limerick, 2018). This trend represents one of the most important challenges according to a transdisciplinary approach (Wognum et al., 2019). In factories of the future, robots (including new safety systems) and other complex CPS will allow reducing the worker physical effort and compensating many worker limitations due to age, inexperience, inappropriate skill, etc. However, workers will increasingly have to program, manage and maintain manufacturing systems, therefore, the enhancement and support of their cognitive skills will become increasingly important to create human-centred workplaces. In this context, new risks and stressors will need to be addressed (Birkel et al., 2019). For this aim, industry 4.0 should push towards the development of methods and tools for a continuous adaptation of workplaces to the workers' capabilities considering also the respective criteria and requirements of health and safety at work. Systems or framework to enable unobtrusive and integrity-protecting monitoring of workers will be needed.

There are different techniques for ergonomics assessments, based on self-reports on perceived workload (e.g., NASA-TLX, SWAT, MCH) or observational scoring models (e.g., RULA, OCRA, REBA). Both are popular in industrial environments (Westgaard and Winkel, 2011), however, they are lacking in objectivity and completeness. The use of physiological parameters is often limited to single analysis to define (re)design criterions (e.g., human-robot collaboration (Arai et al., 2010)) or simulate tasks related to specific sector (e.g., aviation (Hidalgo-Muñoz et al., 2018)). Objective measures of a person's behaviour and effort is not used as a day to day tool due to its complexity and 
obtrusiveness (Shafti et al., 2016). However, with advances in IoT their regular use in the near future seems possible. The literature survey of Ruppert et al. (2018) demonstrated that smart sensors and wearable devices can enable the operators' integration into the concept of smart factories. IoT systems are an opportunity to simultaneously manage the acquisition of data useful for the evaluation of variables which concretely define a certain environment, process or system in which a person lives, works or is simply physically present. For this reason, the IoT system has been seriously considered in the study because the variables of interest identified were many and to quantify and process them you need the support of an integrated system of multiple tools. Bortolini et al. (2020) proposed one of the first effective research contributions of motion capture technologies for productive and ergonomic analysis of the operator during his work.

In this context, the present work aims to answer to the following research questions:

1 How it is possible to measure the overall workers' experience?

2 How IoT can support the ergonomics assessment?

3 Which is the best way to define and develop a sustainable plant model from a social point of view?

In particular, the paper proposes a method for the sustainable development of factories of the future, matching human factors and IoT. It allows defining, quantifying, measuring, monitoring and improving social sustainability at workplace.

According to this purpose, the remainder of this paper is organised as follows. Section 2 presents the method used to create a system of analysis of the variables of social sustainability in the production sectors for which the welfare of the worker is fundamental, with a view to enhancing and optimising human resources. In Section 3, the method was applied to a real case study in a manufacturing environment, with subsequent presentation of the results and discussion.

\section{Research methodology}

If the above-mentioned scientific literature addressed the wellbeing of the operator and his role in the context of industry 4.0 from different and complementary viewpoints, it also highlighted the lack of holistic and proactive approaches to take care of the operator issue and industrial social sustainability. In fact, there are no frameworks, methods and tools that enrich physical and process perspective of work to understand other relevant aspects in order to enhance the human capital and to consider concretely, constructively, and globally its wellbeing in the working context. As a matter of fact, there is a need for new approaches to support the planning and evaluation of work, in a production context characterised by the presence of human workers and CPS. Therefore, this research defines a method to promote a sustainable plant model from a social point of view, with attention to the needs of the operators within the workshop. In particular, it proposes a methodology to design a proper IoT infrastructure able to acquiring a set of human-related parameters from the plant, in order to evaluate and improve the workers' wellbeing as well as the company performance, as proposed in Figure 1. The proposed model is based on three steps: 
1 measure of the operators' and factory performance by a structure procedure (aim definition, variable and sensors selection, framework creation and data collection)

2 evaluation of the operators' and factory performance by a predefined set of rules

3 improve the operators' and factory social sustainability.

The final aim of the proposed social sustainable plant model should be the achievement of the best trade-off between production objectives and physical-cognitive needs of individuals operating in the production context. However, each specific IoT configuration needs a specific driver for a proper design. Therefore, Step1 consists in defining all framework goals in order to create an organised data network. For this aim, the main goals $(\mathrm{G})$ have been identified and classified, as shown in Table 1.

Figure 1 The IoT framework for human-centred manufacturing (see online version for colours)

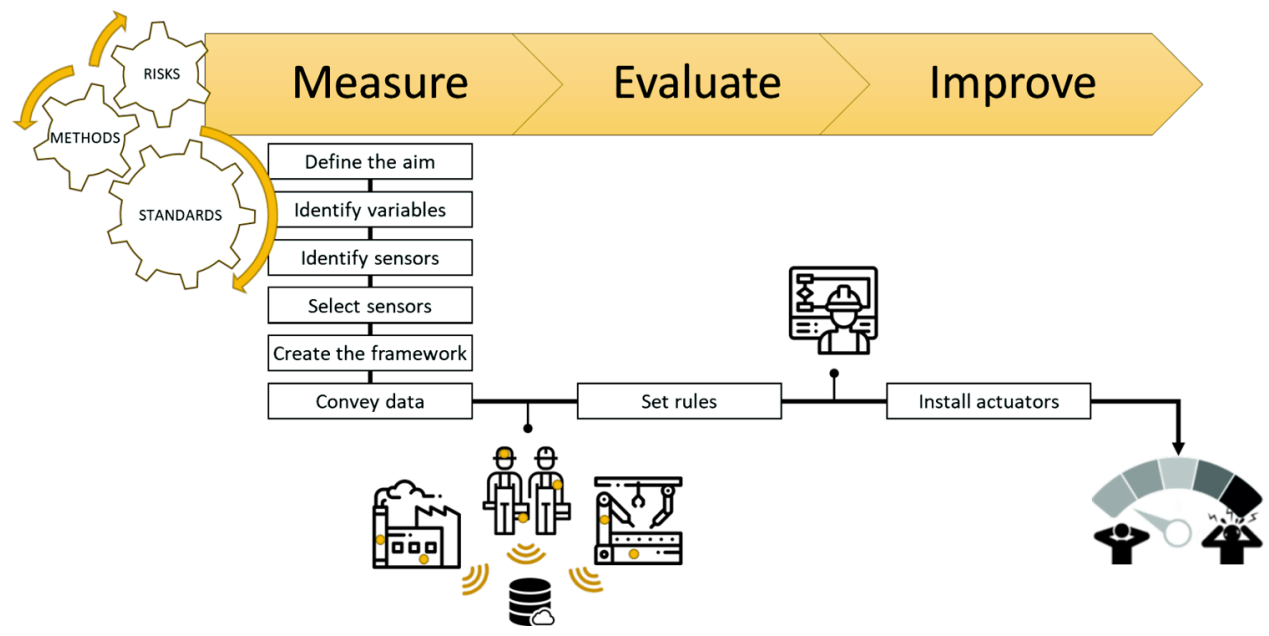

Table 1 Classification of framework goals

\begin{tabular}{llll}
\hline Area & & Goal & \\
\hline G1 & Factory performance & G1.1 & Increase productivity \\
& & G1.2 & Improve quality \\
& G1.3 & Increase organisational incentives \\
& G1.4 & Reduce employee complains \\
& G1.5 & Reduce employee turnover \\
& Perceived workload & G2.1 & Reduce mental demand \\
& G2.2 & Reduce physical demand \\
& G2.3 & Reduce temporal demand \\
& G2.4 & Improve performance \\
& G2.5 & Reduce effort \\
& G2.6 & Reduce frustration \\
& G2.7 & Increase job satisfaction \\
\hline
\end{tabular}


Table 1 Classification of framework goals (continued)

\begin{tabular}{llll}
\hline Area & & Goal & \\
\hline G3 & Work-related diseases & G3.1 & Reduce absenteeism \\
& G3.2 & Reduce accident rate \\
& G3.3 & Reduce sickness absence \\
& G3.4 & Ensure vacation \\
& G3.5 & Reduce musculoskeletal disorders \\
& G3.6 & Reduce stress and mental health disorders \\
& G3.7 & Reduce work-related cancer \\
& Gnowledge & G3.8 & Reduce biological agents exposure \\
& & G4.1 & Increase work capacity \\
& G4.2 & Increase operations skills \\
& Gorkplace & G5.3 & Increase technology skills \\
& & G5.1 & Ensure ergonomic workstation \\
& & G5.2 & Ensure ergonomic environment \\
& G5.4 & Improve human-automation collaboration \\
& &
\end{tabular}

A connected factory can provide a lot of human-related data referring to biometric measures, tasks, environment and the interaction between man and the surrounding ecosystem. The added value is to understand which are significative according to the goal of the analysis. For this aim, the variables of the system (V) and the IoT devices able to collect them as well as alternative sources should be identified in Steps 2 and 3 respectively. To support this phase, all the variables have been classified as shown in the following tables. For each of them, the following items have been specified:

- IoT devices able to collect the variable

- traditional sources such as company DBs, direct observation and operator interview by means of questionnaires, checklists, rating scales, etc.

- references (standards or methods) for the elaboration of data.

Table 2 classifies the characteristics of the worker such as demographic and anthropometric information, acquired skills, personal needs and any physical or cognitive limitations for the performance of specific tasks. These data are necessary for carrying out a tailored ergonomic analysis. For example, operators with scoliosis and hyperlordosis, if present in a relevant form, have more chances of having back problems associated with their working activity.

In general, the worker's characteristics, due to their nature, are collected manually by an ergonomist by interview or questionnaire.

The second category of variables refers to biometric parameters that can be measured during job activity (Table 3 ). These are vital parameters that may highlight excessive physical exertions or indicate particularly stressful conditions, such as respiratory and cardiac frequency. In addition, the Galvanic skin response (GSR) can be easily collected 
by low-cost sensors; it measures the variations in the electrical characteristics of the skin, following the variation of the human body sweating. Also the electroencephalography (EEG) signal that gives indications on cognitive activity, and the electromyography (EMG) signal that provides indications on muscle involvement, can be considered. Finally, eye parameters like blinks, pupil diameter, or fixations and saccades duration, can be monitored to detect fatigue or evaluate the level of concentration/attention. It is worth to specify that the above-mentioned physiological measures are often combined to ensure a higher accuracy in recognising potentially risky conditions (e.g., stress detection (Can et al., 2019)). Finally, there are all the information that allows an accurate description of postures and movements, considering other risk elements such as frequency, strength, duration and stereotypy. The collection and elaboration of the worker's biometric measures can be supported by several wearable sensors and well-known methods for postural risk analysis.

Table 2 Matching between worker's characteristics, data source, data elaboration methods, and reference standards

\begin{tabular}{llllll}
\hline \multicolumn{2}{l}{ Worker's characteristics } & & & Source & Reference \\
\hline V1 & $\begin{array}{l}\text { Demographic } \\
\text { variables }\end{array}$ & V1.1 & Gender, age & DB & \\
V2 & Anthropometry & V2.1 & Anthropometric measures & Direct acquisition & ISO 7250 (2017), \\
& V2.2 & Body mass index & Interview & ISO 15535 (2013) \\
V3 & $\begin{array}{l}\text { Functional } \\
\text { capabilities }\end{array}$ & V3.1 & $\begin{array}{l}\text { Reduced functional } \\
\text { capabilities }\end{array}$ & DB, Interview & \\
V4 & Knowledge & V4.1 & Skills & DB, Interview & \\
& V4.2 & Expertise & DB, Interview & \\
V5 & Personal needs & V5.1 & $\begin{array}{l}\text { Family composition, mobility, } \\
\text { leisure, diet }\end{array}$ & DB, Interview & \\
\hline
\end{tabular}

Table 4 classifies all the variables (V) related to the task in order to perform an ergonomic evaluation of the biomechanical overload of the whole body. In order to evaluate the task-related risks in an accurate and exhaustive manner, it is essential to perform a systematic decomposition of operations and movements in standardised work units, identifying times and execution modalities. Both 'dynamic' and 'static' actions and the relative duration and frequency must be monitored. Actions that require the use of a force are also included. They can be assessed using dedicated instruments or interviews to workers who are asked to describe the subjectively perceived muscular effort related to a certain body segment. Also, the use of force must be quantified temporally. In the case of manual handling of loads, it is necessary to keep track of the object weight and the distances travelled. In the case of precision movements, an important aspect is related to the size of the work areas. Specific indicators can be defined and used to evaluate cognitive activity in relation to the information understanding, initiatives undertaken, solved problems, level of attention, mental workload and so on. In this case, it is advisable to keep track of the work instructions provided in order to identify opportunities for improvement to simplify the task execution. In this case, a low-cost EMG bracelet can be used to monitor most of physical activities and smart glasses (or eye tracker) can support the analysis of the cognitive ones. 
Table 3 Matching between worker's biometrics measures, data source, data elaboration methods and standards

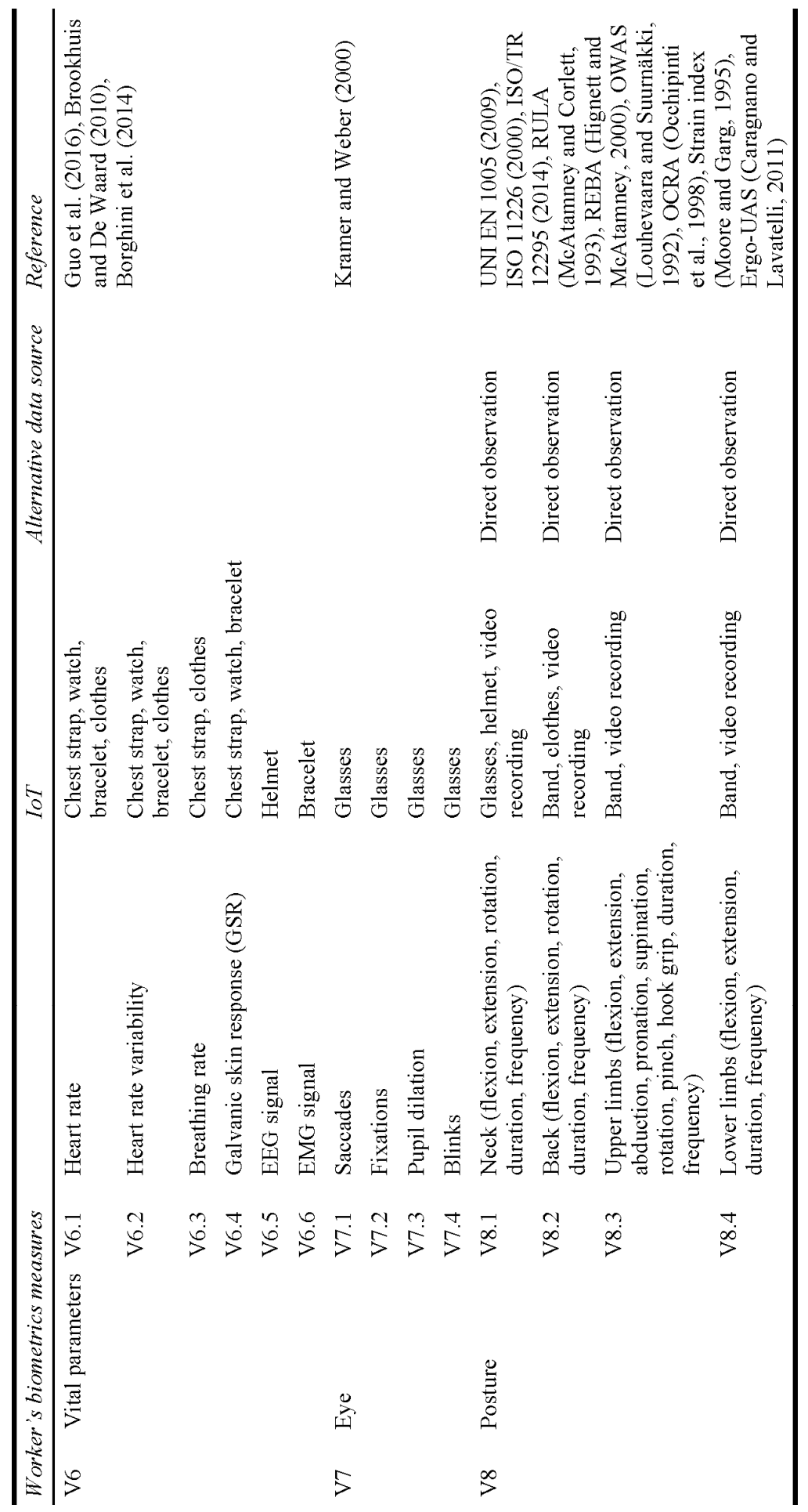


Table 4 Matching between task measured parameters, data source, data elaboration methods and standards

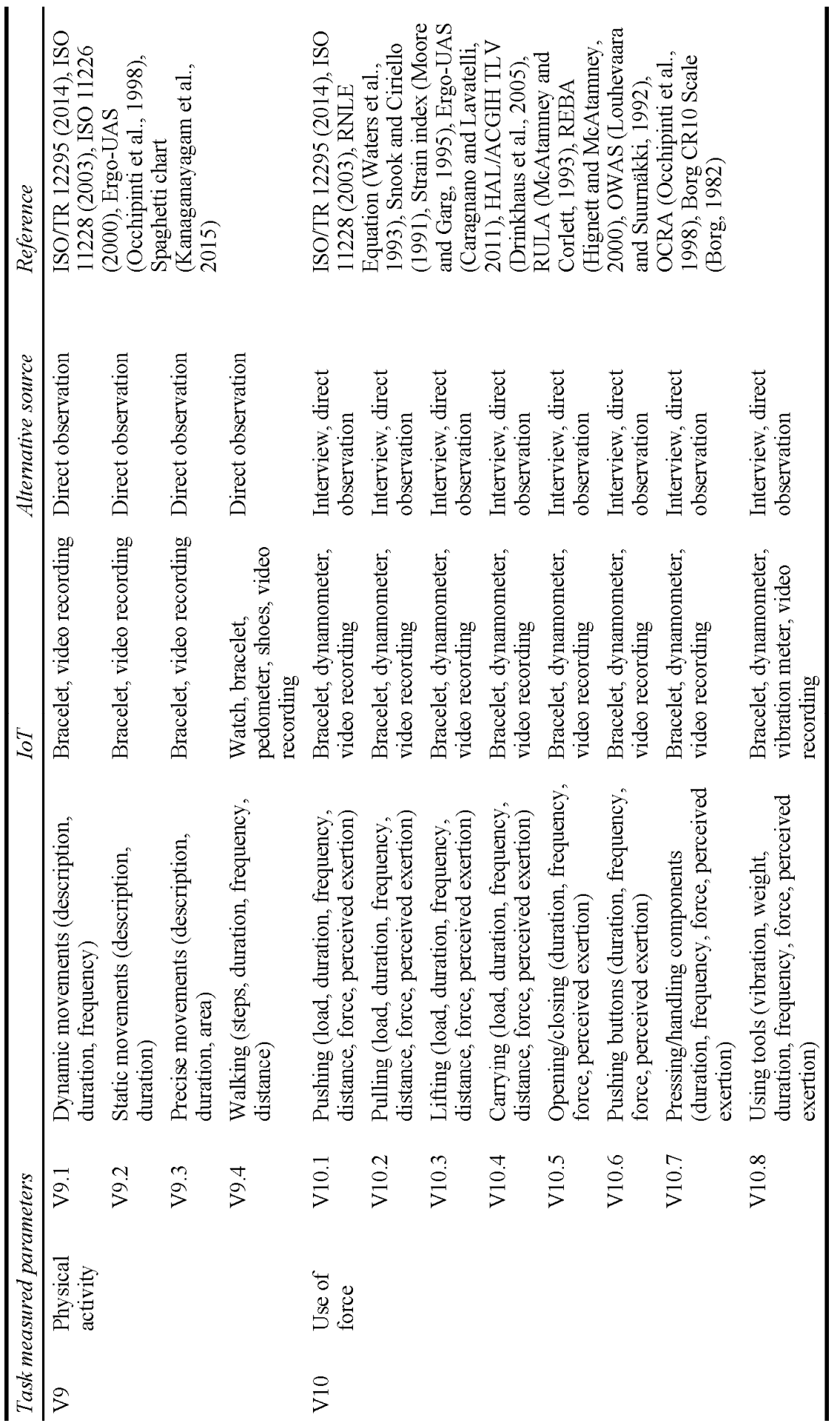


Table 4 Matching between task measured parameters, data source, data elaboration methods and standards (continued)

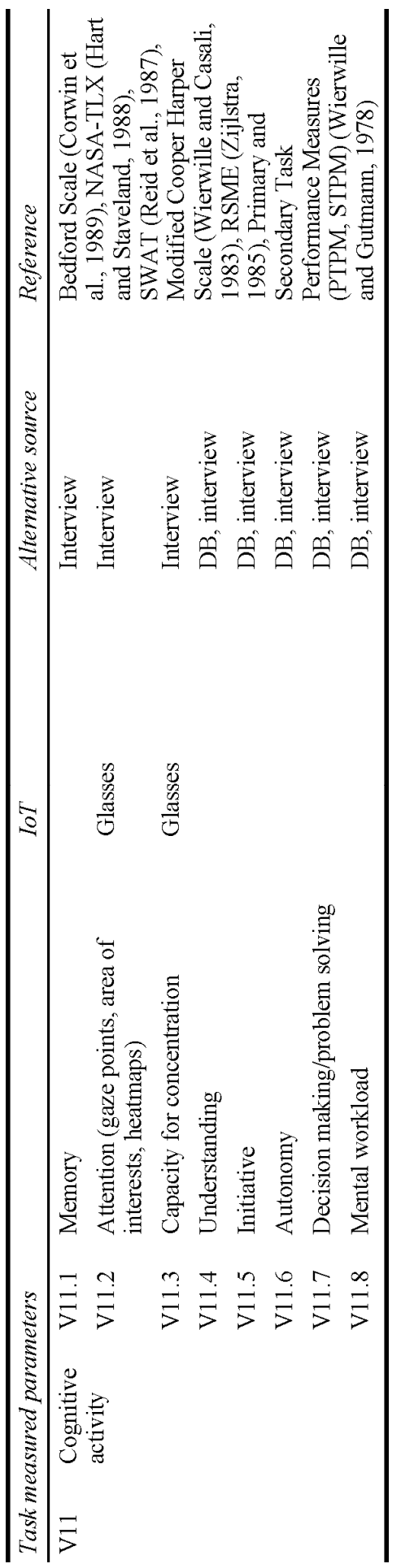


Table 5 Matching between workplace measured parameters, data source, data elaboration methods and standards

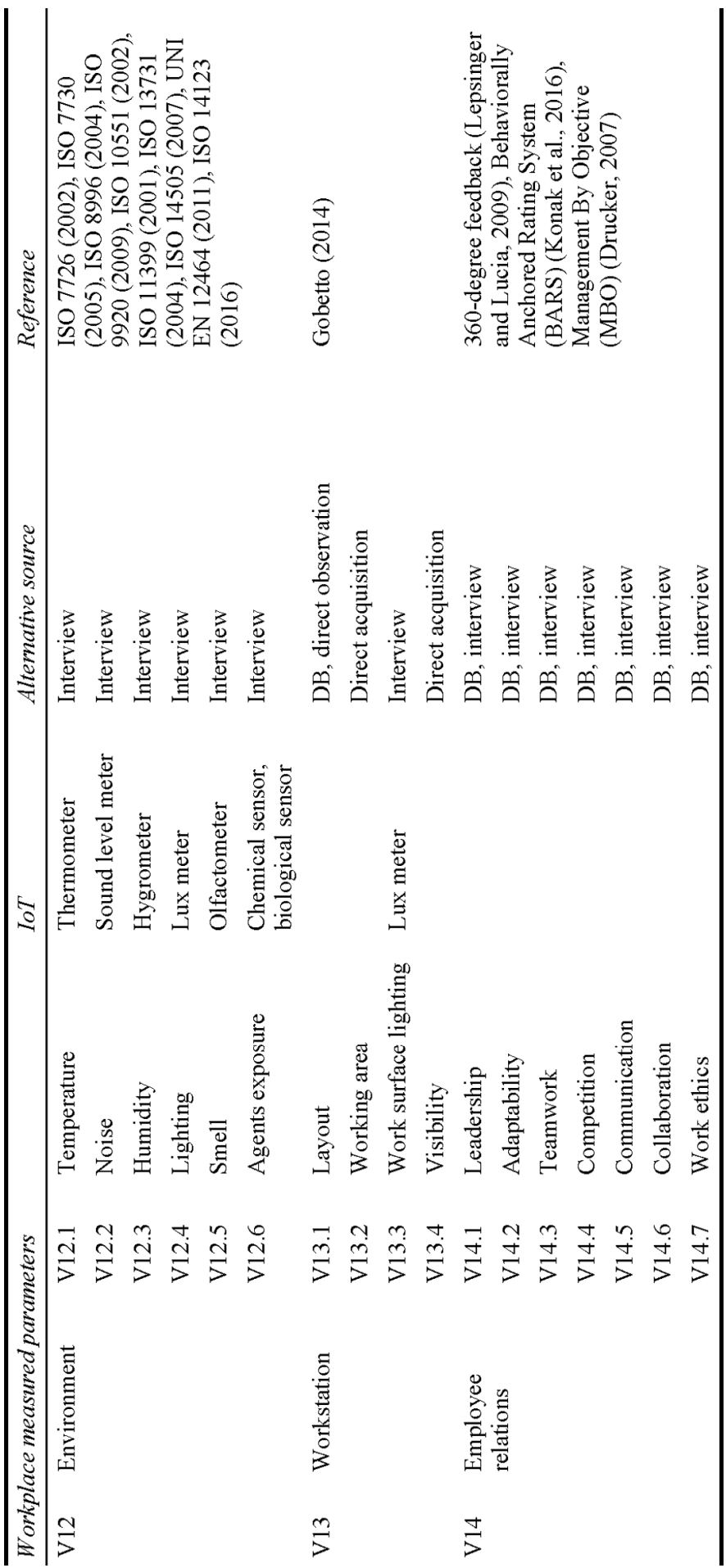


Table 5 Matching between workplace measured parameters, data source, data elaboration methods and standards (continued)

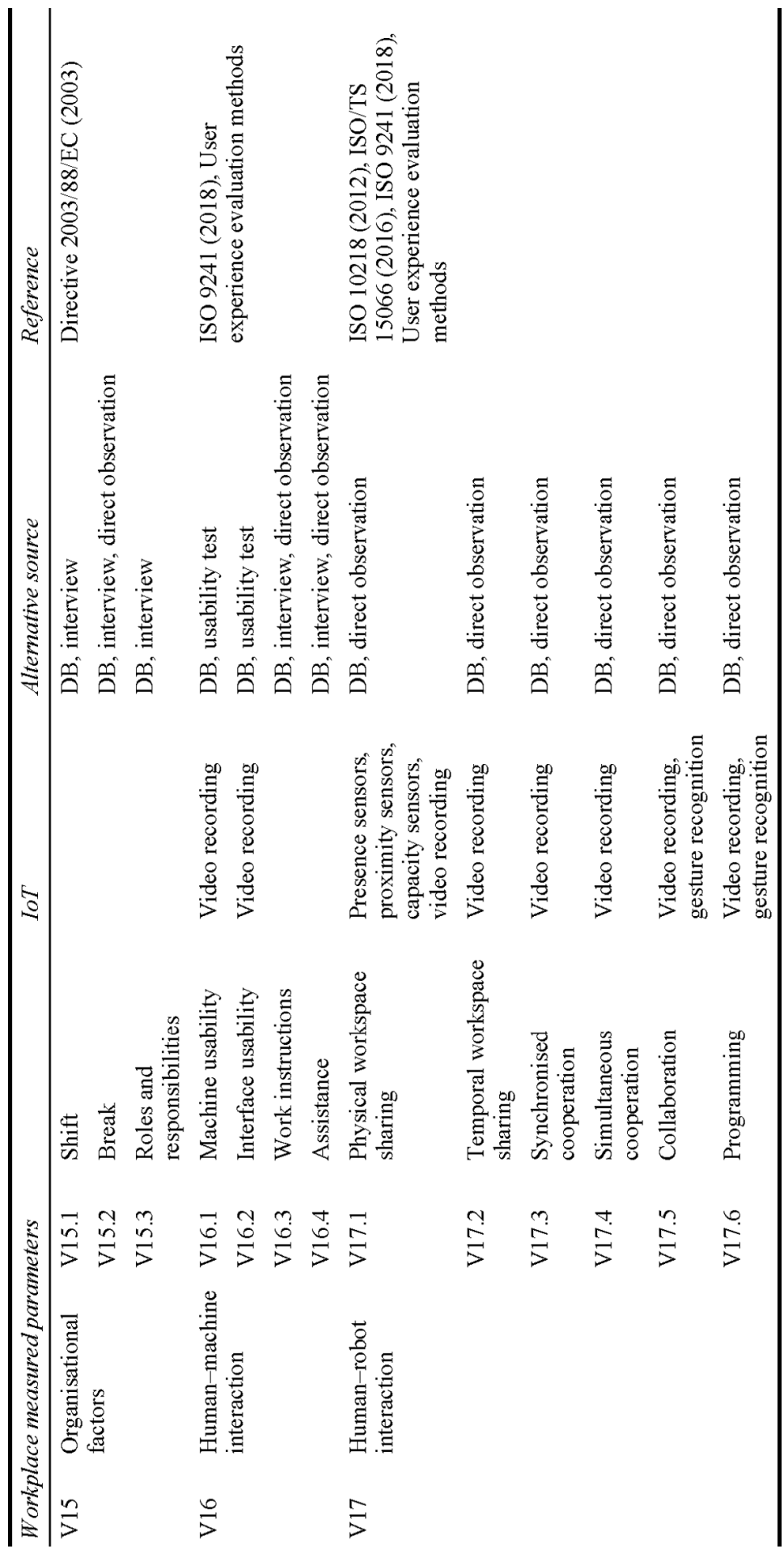


There is strong evidence from the literature that MSDs are not exclusively linked to the biomechanical factors of posture, strength, repetition and duration, but also to the organisation of work and the psychosocial aspects of the working context: work content and scheduling, relationships, errors, etc. In other words, all factors that directly or indirectly influence the quality of life of workers must be considered. For this aim, in Table 5 all variables that characterise the workplace are considered:

- environment, in terms of microclimate, lighting, noise, odours and exposure to agents

- workstation, in terms of layout, work area, work surface lighting and visibility

- human-human interaction that aims to evaluate the operators' behaviours, attitudes and ability to work in a team

- human-machine interaction, evaluated by the most common usability indicators such as task success, time taken, errors committed, etc.

- human-robot interaction, which includes all the information needed to define the task execution modalities in terms of space (physical and temporal) and product sharing, systems enabling a safe collaboration and robot programming techniques.

Workplace data variables are mainly collected through environmental sensors, workers' self-assessment, and direct observation or retrieved by company data.

In Figure 2, a matching matrix between goals and variables is proposed. It aims to support the selection of most proper variables according to the specific framework aims, to implement the proposed methodology. Workers' skills and expertise are strictly correlated to the all goal areas. Indeed, the investment in training and continuous development of employees allows making them feel more valued, competent and confident in their roles; boosting their performance (productivity and quality); increasing the risks awareness; and encouraging a safely use of equipment and the respect of ergonomics principles. Workers' characteristics (age, gender, anthropometric measures) and physiological measures allow better understanding the overall effort to which workers are subjected and possible risks to which they are most exposed. Workstation characteristics and the non-ergonomic execution of manufacturing activities in terms of posture, frequency, load, etc. directly influence productivity, quality, the likelihood of accidents and the onset of work-related disorders, which in turn can generate absenteeism and complains. Similarly, frustration, dissatisfaction and work-related stress can be generated by complex tasks that require cognitive skills that do not fit the workers' capabilities and human-machine interaction, as well as difficult employee relations. Organisational factors can mainly give rise to an excessive workload, which in turn influence the worker fatigue and concentration. Consequently, an appropriate management of shifts/breaks and a proper job allocation can reduce the likelihood of human errors and accidents.

Once selected variables and the data source, the selection of sensors occurs (Step 4). It is based on multiple criteria such as cost, accuracy, intrusiveness, interoperability, sensitivity to external events/sources, etc. and the relative importance assigned by the company. This step should focus on minimising the costs and the equipment. Simpler is the network, simpler will be data interpretation. To simplify here do not means to have less information but avoiding infobesity. In a lifecycle perspective, more sensors mean more maintenance, more updates, and more IoT variables. 
Figure 2 Matching between goals (G) and variables (V)

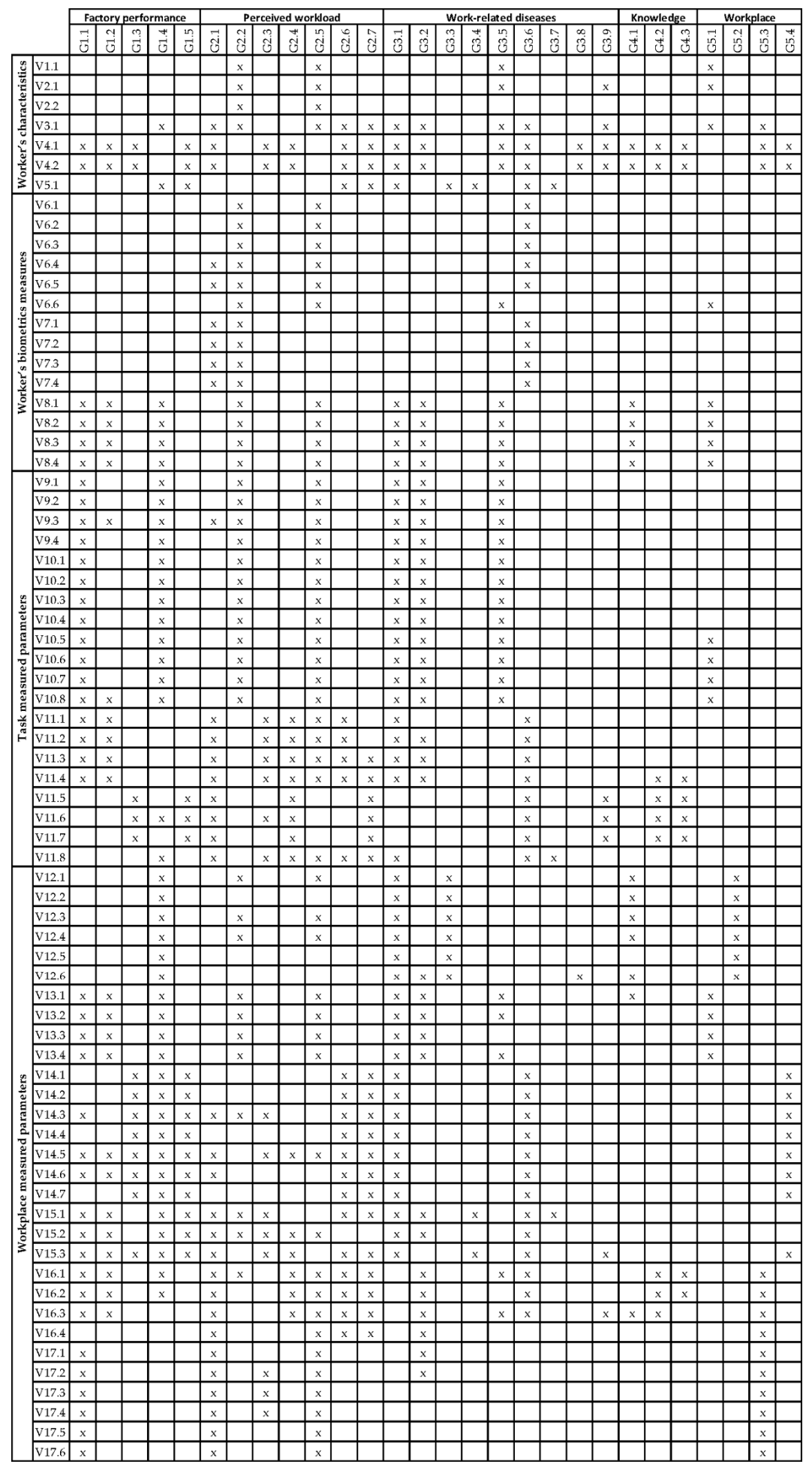


In Step 5 the framework is assembled in the environment. It permits to realise an intelligent ecosystem where data generates corrective actions that should be executed manually or automatically. This step is strictly correlated to Step 6. In fact, it is necessary to convey data in a single device (e.g., database manager) in order to properly collect, manage and elaborate them.

According to the standard and the selected evaluation method, the analysis of the data allows identifying which activities have a greater impact on the operators and, through intelligent algorithms, define the corrective actions (Scafà et al., 2019) to be implemented in order to modify the productive environments towards their needs, defining a dual functioning paradigm of human-machine integration. For this aim, a set of rules should be defined (Step 7). They should manage the influence between variables in order to exclude false alarms; verify the presence of a risk by using multiple sources and detect possible anomalies by correlating multiple factors. The final goal is to define the optimal conditions for the 4.0 operator that interacts with advanced technology systems (collaborative robots, augmented reality technologies, etc.) towards the standardisation of advanced skills necessary for the management of the factory of the future.

Finally, the installation of proper actuators (Step 8) enables the automatically execution of corrective actions according to the rules defined in the previous step.

\section{Industrial case study}

The case study has been realised in collaboration with an Italian SME. It is one of the main manufacturer of rubber and polyurethane soles for shoes in Italy and also worldwide. The company was already committed to the mission of corporate sustainability and joined this research in order to explore the adoption of innovative methods and wearable devices to benefit social sustainability. In fact, in 2017 it has drawn up the global reporting initiative (GRI), which encompasses the main global reference standards for reporting the sustainability performance of an organisation/ enterprise; the particular GRI 403 concerning health and safety in the workplaces. The company has an average production capacity of 14 million soles per year, about 90,000 per day. The number of employees is 247, of which 170 are workmen. The production area is subdivided in departments, each for a different phase of soles manufacturing.

The study involved four operators. The working area involved in this case study is the last phase of the painting process, where the soles are boxed and packed to be shipped (Figure 3). This area consists in a 70 sqm surface and usually occupied two operators.

The operators observed and analysed perform the same operations; average data are shown. In particular, they take soles from a conveyor belt and pack them into boxes. That conveyor belt is the last part of the semi-automated painting machine where the soles gradually flow after drying phases. The conveyor belt collects 1100 soles per hour. This area is active two shifts out of five days a week. The morning shift starts at 5:00 am to 1:00 pm; the afternoon shift is from 1:00 pm to 9:00 pm. For each shift, there are two operators and there is a break of 20 minutes after $4 \mathrm{~h}$. 
Figure 3 Working area of the industrial case study (see online version for colours)
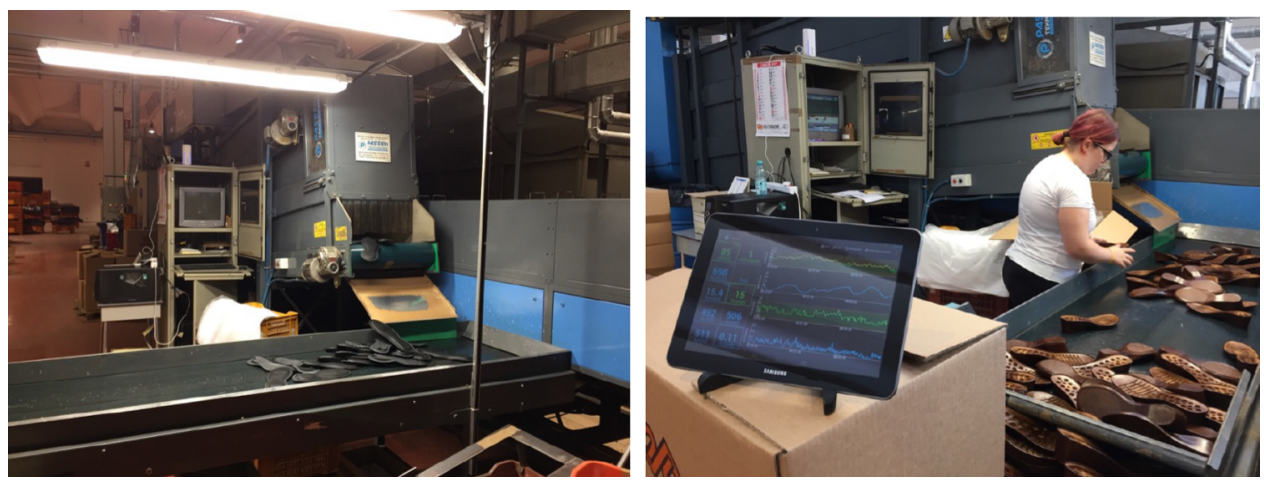

The soles are produced in batches. This means that the same product is always produced in each shift on the conveyor belt. Empty boxes are prepared and positioned on the working stand. When the box is ready on its support, the operator proceeds to print the box label according to the production schedule. Each box has its label showing the model, size and quantity. The PC is located near the box holder. Then, the product picking and packaging began. The products flow on the conveyor belt, and the operator selects the correct size and pairs and fill the box. Paint quality control is intrinsic to the packaging task. Soles are packed in layers and divided by plastic foil. There is a stack of sheets that the operator must separate then put in the boxes in order to ensure that the soles do not damage during transport to the customer. Before the close, each box must be filled with the right number of soles. Periodically, an operator with a forklift truck picks up the complete pallet and transfers it to the finished product warehouse. It is worth specifying that only one operator interacts with the computer to print the label, which will be placed on the boxes.

Considering the scenario and the steps presented in the method the main goals have been identified:

- $\quad$ reduce mental demand (G2.1)

- $\quad$ reduce physical demand (G2.2)

- $\quad$ reduce effort $(\mathrm{G} 2.5)$

- $\quad$ reduce musculoskeletal disorders (G3.5)

- $\quad$ reduce stress and mental health disorders (G3.6)

- $\quad$ ensure ergonomic workstation (G5.1).

The study involves the collection of data directly on the person, for this reason an agreement was shared with the workers who participated voluntarily. This is very important to obtain reliable data: the operator should accept the evaluation positively. In fact, if the evaluation is not fully shared, the data cannot be classified as valid.

At this point a parameters selection was carried out choosing through the goals and variables matrix (Figure 2). The variables matching included all the parameters excluding only some of them: 
- $\quad$ noise (V12.2)

- $\quad$ smell (V12.5)

- $\quad$ agent exposure (V12.6).

The rest of the variables should be considered to achieve the goals proposed. To be noticed, it is that some of the parameter variables were in common in some goals, thus, the sensors selection consisted in a sum of those variables to be monitored through the same wearable devices:

- chest band to record vital parameters such as heart rate, breath rate, and back posture and body motions (vector magnitude units data, VMU)

- glasses with electrooculogram sensors to monitor eye movements such as blinks and fixations.

Data from the wearable sensors were analysed with specific algorithms in relation with anthropometric measures and specific operator characteristics (variables in Table 2, V2).

Environmental features such as temperature has been taken into account.

The first test was performed in the morning shift. The pre-test started at 4.15 a.m. to set up the data acquisition devices. To visually monitor the operation, a camera was placed near the machine. The video recording allows seeing the operator in action both on the picking of the product and during the transport phase of the completed box.

The operator has been named as OP. The operator monitored is specialised in packaging, is a woman, $1.60 \mathrm{~m}$ high, weights $80 \mathrm{~kg}$ and is 22 years old.

The operator was asked to wear all the technological sensors necessary for data acquisition. After the installation of the smart band, the subject was instructed to wear the glasses with sensors.

At 5 a.m. the shift began, and data acquisition was started. During the campaign, the observation was done in a safe area where there was no obstruction with the work operations. All the devices were connected.

The operations sequence was repeated for the whole duration of the shift. After for hours there is a break time of $20 \mathrm{~min}$.

The test lasted for $5 \mathrm{~h}$, to cover most of the working activities including the break. The operator was monitored even during the break, to understand differences in mental load and vital signs. At the end of the test, the sensors were switched off and removed by the operator. The operator reported that devices did not affect her job.

The second test was performed in the afternoon shift and it had the same duration as the first test. This second test deserved to identify a difference in performances in different daytime.

\section{Results}

By returning to the goals indicated previously, the results are presented after data elaboration. In fact, for each specific sensor adopted, raw data were extracted and processed with algorithms that normalised data among workers on the basis of the baseline, classifying the type of physical workload and cognitive activity, for the given packaging task. 


\subsection{Physical workload}

The thoracic smart band was used to evaluate the physical workload by measuring different variables (e.g., heart rate, breath rate, trunk bending); they can be divided into two main categories: assessment of back posture, and intensity of the activity performed.

Data analysis concerning back posture during the morning shift displayed a frequency of bending for less than $20^{\circ}$ (acceptable condition) for the majority of time (almost $95 \%$ of the activity duration), as well as the afternoon shift. Comparing the two shifts, a slight difference between the warning conditions and the critical ones (Table 6). The reason of such a difference is in the different storage in the two shift; indeed, in the afternoon shift the storage at the line-side required pallets with less boxes stacked, so the implement made more bending of the back towards the base of the pallet. Lifting and carrying analysis were equal for both shifts because the operator managed the same number of boxes (No. 20), in the same range of weight (from $10 \mathrm{~kg}$ to $15 \mathrm{~kg}$ ), walking roughly the same distances (4 meters, from the box stand to the boxes stock). However, the NIOSH Variable Lifting Index was higher, due to the awkward posture to stock the boxes on the lowest ledge (Table 7).

Table 6 Back posture assessment (according to ISO 11226) (see online version for colours)

\begin{tabular}{lcc}
\hline Back posture & Morning shift $(\%)$ & Afternoon shift $(\%)$ \\
\hline Bend $\leq 20^{\circ}$ & 94.9 & 95.91 \\
$20^{\circ}<$ Bend $\leq 60^{\circ}$ & 5.0 & 3.89 \\
Bend $>60^{\circ}$ & 0.06 & 0.20 \\
\hline
\end{tabular}

Table 7 Manual lifting and carrying assessment (according to ISO 11228-1)

\begin{tabular}{lc}
\hline NIOSH variable lifting index & Synthetic risk index (carrying) \\
\hline 1.55 & 0.77 \\
\hline
\end{tabular}

Figures 4 and 5 show data recording about the physical effort based on heart rate signal. Performing the same tasks, reactions are different during the day. To understand if any dependency occurs, HR data for the two shifts on are compared in terms of the operator vital signals response. The graphs compare the heart rate classified in the different categories of physical intensity (Norton et al., 2010). It is to note that in the morning shift there is a medium HR of 95 BPM, in the afternoon shift, the medium HR is 104 BPM. The activity difference was also confirmed by the Vector Magnitude Units data (VMU) used to indicate activity level expressed in ' $\mathrm{g}$ ' - units of gravity, $9.81 \mathrm{~m} / \mathrm{s}^{2}$ :

- $0.2 \mathrm{~g}$ - roughly equivalent to a walking level of activity

- $0.8 \mathrm{~g}$ - roughly equivalent to a running level of activity.

In the cases analysed it was found that an average of $0.13 \mathrm{~g}$ for the morning shift and $0.15 \mathrm{~g}$ for the afternoon shift. It is to note that the medium temperature for the period was of $27.8^{\circ} \mathrm{C}$ during morning shift and $30.3^{\circ} \mathrm{C}$ in the afternoon shift. Temperature was affected by outside conditions (Italy, summer season). Then, the little difference in terms of heart rate would be explained by the temperature difference as confirmed by Davies and Maconochie (2009). 
Figure 4 Operator HR-activity classification data in the morning (see online version for colours)

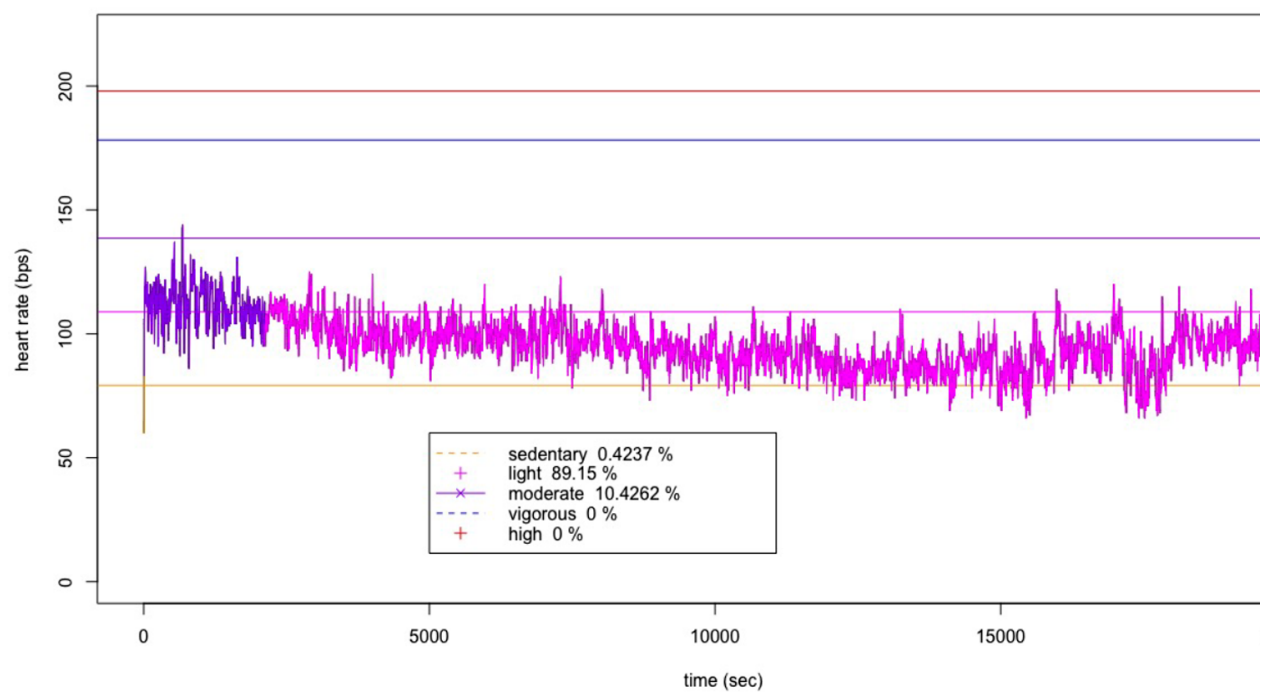

Figure 5 Operator HR-activity classification data in the afternoon (see online version for colours)

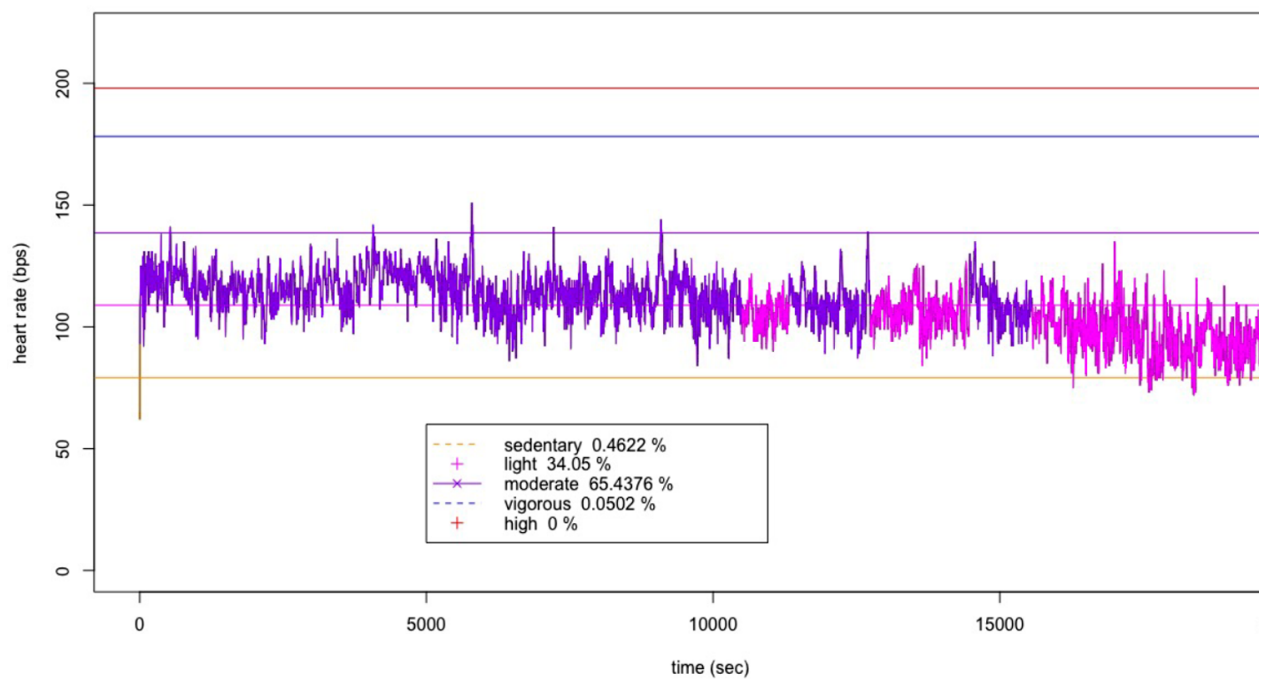

However, there is another impacting variable on the physiological human response: the product. In fact, during the two shifts there were different soles to manage. Weight and shape of soles affected the performance of the operator. Bigger soles (e.g., with hells) are more difficult to pick and verify in respect of thinner ones. After the data correlation, it was asked the operator if she noted the difference in terms of performance from the two shifts and she confirmed a (slight) difference in terms of activity. The morning shift defines the same productivity of the afternoon shift. Temperature and products should be mitigated in order to reach best performances. 


\subsection{Cognitive load}

Data obtained from the smart glasses to monitor the electrooculogram signal returned some issues to explore. Considering the relation between blinks and mental workload, the evidence is that after $1 \mathrm{~h}$ and a half there is a consistent change in terms of cognitive workload according to data from the smart glasses. In fact, after $1 \mathrm{~h}$ and a half there are continuous peaks, meaning blinks in the EOG graph. Figures 6 and 7 represent EOG values for $15 \mathrm{~s}$ of measurement before and after $1 \mathrm{~h}$ and a half. After the latter period, there is a reduction in concentration levels, according to the number and intensity of blinks. Moreover, after $1 \mathrm{~h}$ and a half it is quite difficult to identify clearly peaks according to Figure 7 then it is very complex to correctly associate peaks to operation then understand related impact. This is a first result of the assessment: after $1 \mathrm{~h}$ and a half, the operator is less concentrated. Even after the 20-min pause (after four working hours) the EOG trend was not affected. This means that with an organisational redesign of the area, pause should be rescheduled after $1.5 \mathrm{~h}$ from the shift start.

Figure 6 Electrooculography before 1 hour and a half (see online version for colours)

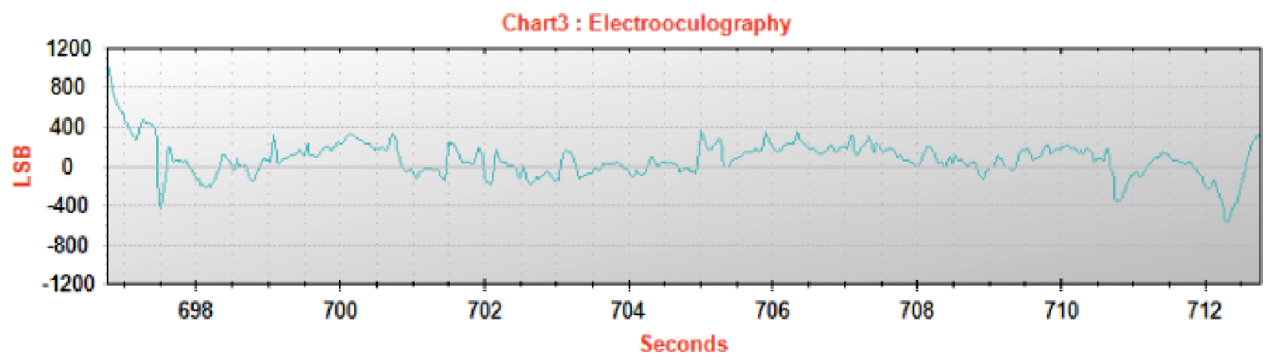

Figure 7 Electrooculography after 1 hour and a half (see online version for colours)

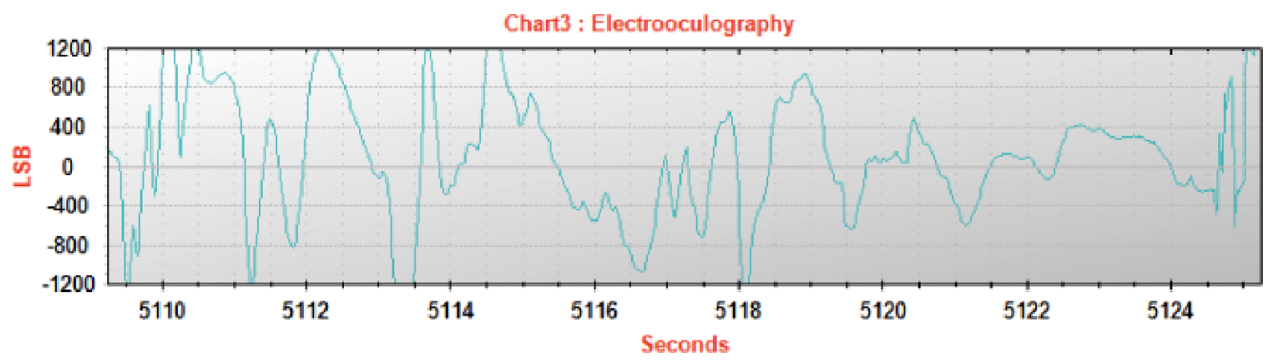

Another interesting issue that presents an increase in mental concentration is the application of PET foils. The operation consists in picking the foils, separate if attached, and lay on between the sole layers in the box. The foils separation has been classified as a high mental demand due to the task precision required. To understand the tasks workload the NASA TLX (Hart and Staveland, 1988) has been submitted to the operator. The tasks considered are the 'counting and soles picking' and the "boxes transportation and storage". The answers given for the different areas of the questionnaire calculated concerning the method gave different ratings. The 'counting and soles picking' task, which included the foils separation, gave a rating of 51 . The highest demand referred to temporal demand due to machinery pace which impacts also on mental demand. The 'boxes transportation and storage' temporal demand gave the same high rating as the 
task above, with the performance and effort demands. The total rating to the second task was of 54. Both tasks did not detect the burden of frustration, unlike a slight presence of the required performance.

\section{Discussion and conclusions}

This study stems from the identification of the need to bring an update of the ergonomic analysis, going beyond the analogue tools used to assess the working conditions in production processes. The work presented focused on describing how a theoretical model can be used for the analysis of human posture and fatigue, i.e., NIOSH and the Norton's study, can be integrated with technological devices and IoT algorithms to specify, analyse and support the assessment of working conditions, associated with specific variables. The integration of all the variables as in the model reported, proposes a global analysis of human work, but at the same time it can be evaluated individually and intervene on the specific variable. The classification of the 'goal' variables is important to ensure a satisfactory job both from the point of view of performance and from the ergonomic, physical and psychological point of view of the worker. These indicators are influenced by several variables that characterise the work environment. The search for the individual variables is supported both by the legislation that protects the occupational safety and health of workers and by the scientific studies mentioned above that support the relationship between them. Not considering these objectives means not completely considering the working context. The study presented a methodology for promoting social sustainability in an intelligent factory and reported a case study in which the proposed method was applied within an SME. IoT devices were used to collect data on workers' characteristics, work environment and work development. During the case study, the interpolation between the recorded social sustainability data and the workers' information suggests the importance of a structured data management and an adequate data acquisition system. The comparison with previous risk assessment based on traditional employee interviews highlighted the two main benefits of the proposed approach: a more objective analysis, that is independent from the users' skills and habits, and a wider set of data collected, and available for further improvements. In particular, the proposed objective measurements provided a potentially accurate and optimised estimate of the impact of the human factor on work. Through the proposed algorithms, variables that influence human behaviour are integrated in different ways, at the same time, and single parameter can be modified according to variable working conditions. As a result, the optimisation of human work improved the quality of working conditions and the efficiency of the production system, and thus the achievement of selected goals. As a consequence, if the company and the worker do not share the values, the analysis is useless because of an intrinsic manipulation of the data. In fact, if a worker assumes that the analysis is aimed at controlling him and his efficiency, he must have a behaviour, whether he accepts the test, which compromises the results. In this context, worker motivation was also crucial: the workers must understand the opportunity and benefits of the proposed approach to push for social sustainability. Only with this premises, the analysis allows to identify the critical points for the operator. These were inefficiencies and costs for the company.

On the other hand, the study has few limits. The main limit is certainly due to the size of the sample, which is not statistically significant. Increasing the sample size and 
analysis times will be done to support the proposed methodology more effectively. In addition, future work will focus on defining a set of rules that support the selection of the most appropriate corrective actions, assessing their effectiveness in mitigating the identified risk, simulating their implementation to verify the generation of new risks and quantify their benefits based on the different domains of KPIs.

\section{References}

Arai, T., Kato, R. and Fujita, M. (2010) 'Assessment of operator stress induced by robot collaboration in assembly', CIRP Annals - Manufacturing Technology, Vol. 59, pp.5-8.

Birkel, H.S., Veile, J.W., Müller, J.M., Hartmann, E. and Voigt, K-I. (2019) 'Development of a risk framework for Industry 4.0 in the context of sustainability for established manufacturers', Sustainability, Vol. 11, No. 2, p.384.

Borg, G.A. (1982) 'Psychophysical bases of perceived exertion', Med. Sci. Sports Exerc., Vol. 14, pp.377-381.

Borghini, G., Astolfi, L., Vecchiato, G., Mattia, D. and Babiloni, F. (2014) 'Measuring neurophysiological signals in aircraft pilots and car drivers for the assessment of mental workload, fatigue and drowsiness', Neuroscience \& Biobehavioral Reviews, Vol. 44, pp.58-75.

Bortolini, M., Faccio, M., Gamberi, M. and Pilati, F. (2020) 'Motion analysis system (MAS) for production and ergonomics assessment in the manufacturing processes', Computers \& Industrial Engineering, Vol. 139, p.105485.

Brookhuis, K.A. and De Waard, D. (2010) 'Monitoring drivers' mental workload in driving simulators using physiological measures', Accident Analysis \& Prevention, Vol. 42, No. 3, pp.898-903.

Burgess-Limerick, R. (2018) 'Participatory ergonomics: Evidence and implementation lessons', Appl. Ergon., Vol. 68, pp.289-293.

Can, Y.S., Arnrich, B. and Ersoy, C. (2019) 'Stress detection in daily life scenarios using smart phones and wearable sensors: a survey', Journal of Biomedical Informatics, Vol. 92, p.103139.

Caragnano, G. and Lavatelli, I. (2011) 'Ergonomia e produttività obiettivi inscindibili', Associazione MTM Italia, Malnate, Italy, p.3.

Corwin, W.H., Sandry-Garza, D.L., Biferno, M.H., Boucek, G.P., Logan, A.L., Jonsson, J.E. and Metalis, S.A. (1989) Assessment of Crew Workload Measurement Methods, Techniques, and Procedures, Volume I - Process, Methods, and Results (WRDC-TR-89-7006), Wright Patterson Air Force Base, $\mathrm{OH}$.

Davies, P. and Maconochie, I. (2009) 'The relationship between body temperature, heart rate and respiratory rate in children', Emergency Medicine Journal, Vol. 26, pp.641-643.

Directive 2003/88/EC (2003) Directive 2003/88/EC of the European Parliament and of the Council of 4 November 2003 Concerning Certain Aspects of the Organisation of Working Time.

Docherty, P., Kira, M. and Shani, A.B. (2009) 'What the world needs now is sustainable work systems', in Docherty, P., Kira, M. and Shani, A.B. (Eds.): Creating Sustainable Work Systems, 2nd ed., Routledge, London and New York, pp.1-21.

Drinkhaus, P., Sesek, R., Bloswick, D.S., Mann, C. and Bernard, T. (2005) 'Job level risk assessment using task level ACGIH hand activity level TLV scores: a pilot study', Occupational Journal of Occupational Safety and Ergonomics, Vol. 11, No. 3, pp.263-281.

Drucker, P.F. (2007) The Practice of Management, Harper, New York, 1954; Heinemann, London, 1955; Revised ed., Butterworth-Heinemann.

Eurostat (2019) Persons Reporting a Work-related Health Problem by Sex, Age and Type of Problem [hsw_pb5], http://appsso.eurostat.ec.europa.eu/nui/submitViewTableAction.do 
Gobetto, M. (2014) Operations Management in Automotive Industries: From Industrial Strategies to Production Resources Management, Through the Industrialization Process and Supply Chain to Pursue Value Creation, Springer Verlag, Dordrecht.

Guo, W., Tian, X., Tan, J. and Wang, L. (2016) 'Change in heart rate variability indexes due to high driving workload in turning left at the intersection in real road environment', 3rd International Conference on Materials Engineering, Manufacturing Technology and Control (ICMEMTC 2016), Taiyuan, China, pp.804-807.

Hart, S. and Staveland, L. (1988) 'Development of NASA-TLX (task load index): results of empirical and theoretical research', Human Mental Workload, Vol. 1, pp.139-183.

Hidalgo-Muñoz, A.R., Mouratille, D., Matton, N., Causse, M., Rouillard, Y. and El-Yagoubi, R. (2018) 'Cardiovascular correlates of emotional state, cognitive workload and timeon-task effect during a realistic flight simulation', International Journal of Psychophysiology, Vol. 128, pp.62-69.

Hignett, S. and McAtamney, L. (2000) 'Rapid entire body assessment (REBA)', Applied Ergonomics, Vol. 31, No. 2, pp.201-205.

ISO 10218 (2012) Robots and Robotic Devices - Safety Requirements for Industrial Robots.

ISO 10551 (2002) Ergonomics of the Thermal Environment - Assessment of the Influence of the Thermal Environment using Subjective Judgement Scales.

ISO 11226 (2000) Ergonomics - Evaluation of Static Working Postures.

ISO 11228 (2003) Ergonomics - Manual Handling.

ISO 11399 (2001) Ergonomics of the Thermal Environment - Principles and Application of Relevant International Standards.

ISO 13731 (2004) Ergonomics of the Thermal Environment-Vocabulary and Symbols.

ISO 14123 (2016) Safety of Machinery - Reduction of Risks to Health Resulting from Hazardous Substances Emitted by Machinery.

ISO 14505 (2007) Ergonomics of the Thermal Environment - Evaluation of Thermal Environments in Vehicles.

ISO 15535 (2013) General Requirements for Establishing Anthropometric Databases.

ISO 7250 (2017) Basic Human Body Measurements for Technological Design.

ISO 7726 (2002) Ergonomics of the Thermal Environment - Instruments for Measuring Physical Quantities.

ISO 7730 (2005) Ergonomics of the Thermal Environment - Analytical Determination and Interpretation of Thermal Comfort using Calculation of the PMV and PPD Indices and Local Thermal Comfort Criteria.

ISO 8996 (2004) Ergonomics of the Thermal Environment-Determination of Metabolic Rate.

ISO 9241 (2018) Ergonomics of Human-System Interaction.

ISO 9920 (2009) Ergonomics of the Thermal Environment - Estimation of Thermal Insulation and Water Vapour Resistance of a Clothing Ensemble.

ISO/TR 12295 (2014) Ergonomics - Application Document for International Standards on Manual Handling (ISO 11228-1, ISO 11228-2 and ISO 11228-3) and Evaluation of Static Working Postures (ISO 11226).

ISO/TS 15066 (2016) Robots and Robotic Devices - Collaborative Robots.

Jasiulewicz-Kaczmarek, M. (2013) 'The role of ergonomics in implementation of the social aspect of sustainability, illustrated with the example of maintenance', Occupational Safety and Hygiene, Vol. 6, pp.47-52.

Kanaganayagam, K., Muthuswamy, S. and Damoran, P. (2015) 'Lean methodologies to improve assembly line efficiency: an industrial application', International Journal of Industrial and Systems Engineering, Vol. 20, No. 1, pp.104-116. 
Konak, A., Magluilo, S. and Kulturel-Konak, S. (2016) 'Behaviorally anchored rating scales for teamwork peer assessment', 2016 IEEE Integrated STEM Education Conference, Princeton, NJ, pp.168-172.

Kramer, A.F. and Weber, T. (2000) 'Applications of psychophysiology to human factors', in Cacioppo, J.T., Tassinari, L.G. and Berntson, G.G. (Eds.): Handbook of Psychophysiology, Cambridge University Press, Cambridge, UK.

Lepsinger, R. and Lucia, A.D. (2009) The Art and Science of 360 Degree Feedback, John Wiley \& Sons, San Francisco.

Louhevaara, V. and Suurnäkki, T. (1992) OWAS: A Method for the Evaluation of Postural Load During Work, Institute of Occupational Health, Centre for Occupational Safety, Helsinki.

McAtamney, L. and Corlett, E.N. (1993) 'RULA: a survey method for the investigation of work-related upper limb disorders', Applied Ergonomics, Vol. 24, No. 2, pp.91-99.

Midouhas, H.M. (2017) 'Sustainable business: Toward a nature-centered process', Sustainability, Vol. 10, No. 3, pp.177-183.

Moore, J.S. and Garg, A. (1995) 'The strain index: a proposed method to analyze jobs for risk of distal upper extremity disorders', American Industrial Hygiene Association Journal, Vol. 56, No. 5 , pp.443-458.

Norton, K., Norton, L. and Sadgrove, D. (2010) 'Position statement on physical activity and exercise intensity terminology', J. Sci. Med. Sport, Vol. 13, No. 5, pp.496-502.

Occhipinti, E., Colombini, D. and Grieco, A. (1998) 'OCRA: a concise index for the assessment of exposure to repetitive movements of the upper limbs', Ergonomics, Vol. 41, No. 9, pp.1290-1311.

Peruzzini, M., Grandi, F. and Pellicciari, M. (2020) 'Exploring the potential of Operator 4.0 interface and monitoring', Computers and Industrial Engineering, Vol. 139, 106128, https://doi.org/10.1016/j.cie.2018.12.047

Peruzzini, M. and Pellicciari, M. (2017) 'A human factors assessment model for sustainable manufacturing', Int. J. Agile Systems and Management, Vol. 10, Nos. 3-4, pp.206-230, https://doi.org/10.1504/IJASM.2017.088511

Reid, G., Potter, S. and Bressler, J. (1987) Subjective Workload Assessment Technique (SWAT): A User's Guide, Wright-Patterson AFB, Harry G. Armstrong Aerospace Medical Research Laboratory, $\mathrm{OH}$.

Ruppert, T., Jaskó, S., Holczinger, T. and Abonyi, J. (2018) 'Enabling technologies for operator 4.0: a survey', Appl. Sci., Vol. 8, p.1650.

Scafà, M., Papetti, A., Brunini, A. and Germani, M. (2019) 'How to improve worker's well-being and company performance: a method to identify effective corrective actions', Procedia CIRP, Vol. 81, pp.162-167.

Shafti, A., Lazpita, B.U., Elhage, O., Wurdemann, H.A. and Althoefer, K. (2016) 'Analysis of comfort and ergonomics for clinical work environments', Conf. Proc. IEEE Eng. Med. Biol. Soc., Orlando, FL, pp.1894-1897.

Siemieniuch, C.E., Sinclair, M.A. and Henshaw, M.J.C. (2015) 'Global drivers, sustainable manufacturing and systems ergonomics', Appl. Ergon., Vol. 51, pp.104-119.

Snook, S.H. and Ciriello, V.M. (1991) 'The design of manual handling tasks: revised tables of maximum acceptable weights and forces', Ergonomics, Vol. 34, No. 9, pp.1197-1213.

The Boston Consulting Group (2015) Industry 4.0 the Future of Productivity and Growth in Manufacturing Industries.

UNI EN 1005 (2009) Safety of Machinery - Human Physical Performance.

UNI EN 12464 (2011) Light and Lighting - Lighting of Work Places.

United Nations (2015) Transforming our World: The 2030 Agenda for Sustainable Development, 21 October 2015, A/RES/70/1, https://www.refworld.org/docid/57b6e3e44.html

Waters, T.R., Putz-Anderson, V., Garg, A. and Fine, L.J. (1993) 'Revised NIOSH equation for the design and evaluation of manual lifting tasks', Ergonomics, Vol. 36, No. 3, pp.749-776. 
Westgaard, R.H. and Winkel, J. (2011) 'Occupational musculoskeletal and mental health: significance of rationalization and opportunities to create sustainable production systems - a systematic review', Appl. Ergon., Vol. 42, pp.261-296.

Wierwille, W. and Casali, J. (1983) 'A validated rating scale for global mental workload measurement applications', Proceeding of the Human Factors society Annual Meeting, Vol. 27, No. 2, pp.129-133.

Wierwille, W.W. and Gutmann, J.C. (1978) 'Comparison of primary and secondary task measures as a function of simulated vehicle dynamics and driving conditions', Human Factors: The Journal of the Human Factors and Ergonomics Society, Vol. 20, No. 2, pp.233-244.

Wognum, N., Bil, C., Elgh, F., Peruzzini, M., Stjepandić, J. and Verhagen, W.J.C. (2019) 'Transdisciplinary systems engineering: Implications, challenges and research agenda', International Journal of Agile Systems and Management, Vol. 12, No. 1, pp.58-89.

Zijlstra, F.R.H. (1985) The Construction of a Scale to Measure Perceived Effort, University of Technology, Delft.

Zink, K.J. (2014) 'Designing sustainable work systems: the need for a system approach', Appl. Ergon., Vol. 45, No. 1, pp.126-132. 